\title{
SYNTHESIS OF ZEOLITE FROM CoAl Fly AsH: its Application as Water SORBent
}

\section{Thepparat Klamrassamee1, Prasert Pavasant² and Navadol Laosiripojana ${ }^{1 *}$}

\author{
1 The Joint Graduate School of Energy and Environment, \\ King Mongkut's University of Technology Thonburi, Bangkok, Thailand 10140 \\ Department of Chemical Engineering, Faculty of Engineering, \\ Chulalongkorn University, Bangkok, Thailand 10330 \\ E-mail: thepparat_14@hotmail.com ${ }^{1}$, prasert.p@chula.ac.th.ac.th ${ }^{2}$ and \\ navadol_@@jgsee.kmutt.ac.th ${ }^{1}$
}

\section{ABSTRACT}

Coal fly ash (CFA) was used as raw material for zeolite synthesis using the fusion method. In detail, it was mixed with $\mathrm{NaOH}$ (with ratio of 2.25) and treated under various temperatures. The synthesized zeolite was characterized using various techniques i.e. X-rayfluorescence (XRF), X-ray diffraction (XRD), and BET surface area analysis. It was found that the surface area of the synthesized zeolite was in the range of $49-69 \mathrm{~m}^{2} / \mathrm{g}$ depending on the preparation conditions, compared to the surface area of CFA about $17 \mathrm{~m}^{2} / \mathrm{g}$. In addition, according to the XRD result, it was proven that the form of zeolite was Sodium Aluminum Silicate Hydrate $\left(1.08 \mathrm{Na}_{2} \mathrm{O} \cdot \mathrm{Al}_{2} \mathrm{O}_{3} \cdot 1.68 \mathrm{SiO}_{2} \cdot 1.8 \mathrm{H}_{2} \mathrm{O}\right)$. The synthesized zeolite was then applied as a water sorbent to remove water from ethanol solution (95\%). The testing results revealed that the optimal fusion temperature was $450^{\circ} \mathrm{C}$, which provided maximum percentage of water removal from ethanol solution (from $95 \%$ ethanol to $99.25 \%$ ethanol). For comparison, a commercial-grade molecular sieve was also tested and was found to increase ethanol concentration from $95 \%$ to $99.61 \%$. Hence, it is concluded that our synthesized zeolite provides comparable performance to the commercial-grade molecular sieve.

\section{KEYWORDS}

coal fly ash, zeolite, fusion method, water sorbent 


\section{Introduction}

Nowadays, gasoline is used extensively; thus resulting in shortages and the price also rising rapidly. Ethanol is one of the promising alternative fuels to replace gasoline, as called gasohol. It is produced from digestion and fermentation process using starch and sugar. These processes can produce ethanol about $30 \%$ by volume. Then, it is processed into pure ethanol (99.5\%). The ethanol purification process has two steps: the first step is distillation to increase concentration of ethanol into $95.5 \%$ by volume (cannot increase concentration of ethanol with normal distillation), the second step is ethanol purification ( $99.5 \%$ by volume) using various methods such as zeotrope distillation, water adsorption by using substance adsorption or membrane etc. Thus, the conventional method, adsorption or molecular sieving, is economically worthwhile and effective in production process.

Coal Fly ash (CFA) is a major solid waste from coal-firing power stations. In Thailand, more than 5.1 million tons of fly ash were generated with a tendency to increase every year [1]. According to the treatment process, currently, most of it is dumped in landfills. Furthermore, it can also be applied in road construction and cement production. In the present work, we present an alternative method to increase the value of fly ash by using it for zeolite (or molecular sieve) synthesis. This method is interesting since fly ash is generally composed of $\mathrm{Si}$ and $\mathrm{Al}$ as the major element (in the form of aluminosilicate), with minor amounts of $\mathrm{Fe}$, $\mathrm{Na}, \mathrm{K}, \mathrm{Ca}, \mathrm{P}, \mathrm{ti}$ and $\mathrm{S}$ [2]. Other crystalline minerals are also present in small quantities such as mullite, quartz and lime anhydrite. Theoretically, zeolite are porous aluminosilicate compounds having numerous properties, such as, molecular sieving, high thermal stability, ion exchange capability, water adsorption capability and shape selective catalytic behavior because of their special structure. They are categorized into natural and synthesized types. Usually, synthesized zeolites are preferred over natural ones due to the possibility of adjusting their pore size through different synthesizing techniques. About 24 types of different zeolites are synthesized from CFA amongst which $A, X$ and $Y$ are more valuable because of their extensive catalytic applications in detergent, petroleum refining and petrochemical industries. The two most common methods available for this conversion are hydrothermal and fusion method [3], where the fusion method has advantages on the speed of the reaction [3] and the purity of the final product [4] - [5], whereas the hydrothermal provides a more consistent pattern of the zeolite products. For solid phase reactions like the conversion of CFA, the fusion method is considered more suitable as the hydrothermal is more appropriate for reactions in liquid phase. Previously, Shigemoto et al [6] performed the synthesis of these materials by adding an alkaline fusion stage before conventional fly ash zeolitization. The major crystaline phases found in the fly ash are quartz, mullite and aluminosilicate glass. On the other hand, a large amount of sodium silicate exists in the fused fly ash, which implies that fusion is effective in extraction of silicon from quartz. The conversion of CFA to zeolite has been proposed as a variable method. This is not only to generate a useful adsorbent but also to increase the value of CFA.

This research aims to find the optimal conditions to generate zeolite from CFA by fusion method using $\mathrm{NaOH}$ as the activation reagent. The synthesized materials were then tested for removing water from ethanol solution (vapor phase) under fixed-bed reactor and also compared the performance with the commercial-grade molecular sieve.

\section{The Experiment}

\subsection{Fly ash}

Raw fly ash was obtained from the local coal fired thermal power station which supplies electricity to the pulp process in commercial plantation area in Prachinburi province, Thailand. Chemical characterization analysis by X-ray fluorescence(XRF) results were: $\mathrm{SiO}_{2}=26.8 \%, \mathrm{Al}_{2} \mathrm{O}_{3}=14.77 \%, \mathrm{Fe}_{2} \mathrm{O}_{3}=25.12 \%, \mathrm{~K}_{2} \mathrm{O}=3.16 \%, \mathrm{TiO}_{2}=$ $2.22 \%, \mathrm{CaO}=2.05 \%, \mathrm{MgO}=1.51 \%, \mathrm{SO}_{3}=7.3 \%, \mathrm{NiO}=0.25 \%, \mathrm{Rb}_{2} \mathrm{O}=0.05 \%, \mathrm{SrO}=$ $0.18 \%, \mathrm{Y}_{2} \mathrm{O}_{3}=0.21 \%$ and $\mathrm{ZrO}_{2}=0.33 \%$ by weight.

\subsection{Zeolite synthesis}

Initially, the experiment was performed following the procedure suggested by Molina and Poole [7]. This method started with mixing $2 \mathrm{~g}$ of fly ash with $4.5 \mathrm{~g}$ of $\mathrm{NaOH}$ (to make the $\mathrm{NaOH} / \mathrm{FA}$ of 2.25). The mixture was fused in air at $450^{\circ} \mathrm{C}$ for $1 \mathrm{~h}$ in furnace. In this case, there were chemical products formed through the fusion process. The 
product was crushed and dissolved in $20 \mathrm{~mL}$ of distilled water and mixed in a shaking machine at room temperature for $12 \mathrm{~h}$. Crystallization was then performed under static condition of $90^{\circ} \mathrm{C}$ for $4 \mathrm{~h}$ where the crystal was collected through filtration technique. The crystal was washed several times with distilled water (until the solution reached $\mathrm{pH}$ of 7) and dried overnight at $105^{\circ} \mathrm{C}$. This section was to investigate of temperature in the fusion process. The range of furnace temperature examined was 450,550 and $650^{\circ} \mathrm{C}$. Detail of the installation apparatus are given in Fig.1. The final zeolite product was analyzed for its degree of crystalline using X-ray (XRD) analysis (PHILIPS X'Pert MPD), and was investigated for surface area and pore sizes by BET method.

Figure 1

Scheme of set up apparatus for zeolite synthesis by fusion method

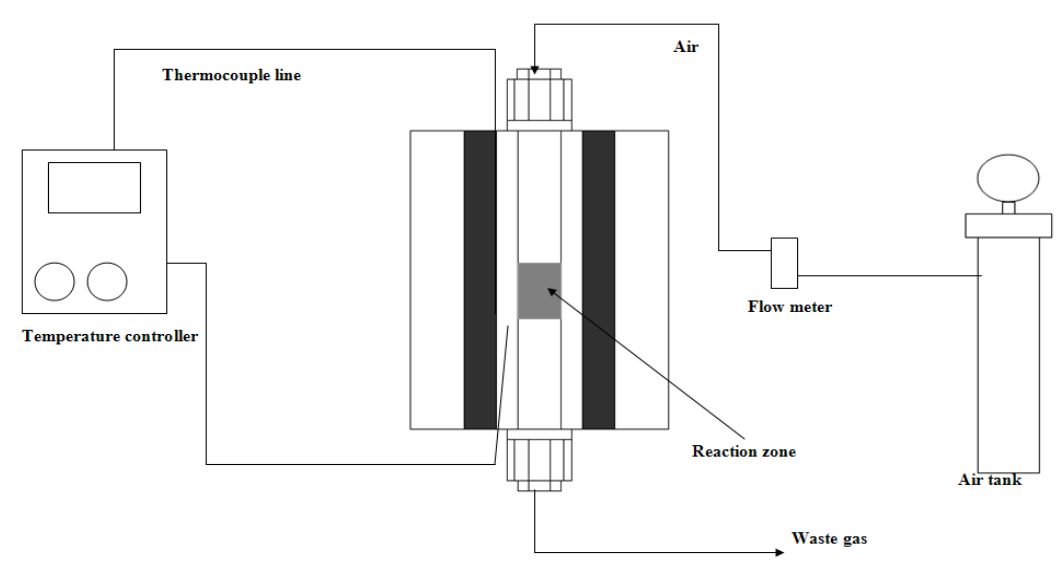

\subsection{Batch adsorption experiment}

Three samples from the zeolite synthesis step were tested for removal of water in ethanol solution in this work. Zeolites were dried in an oven at temperatures of $105^{\circ} \mathrm{C}$ for $24 \mathrm{hrs}$. The fixed-bed adsorber apparatus has been designed as shown schematically in Figure 2.

Figure 2

Scheme of set

up apparatus

for adsorption

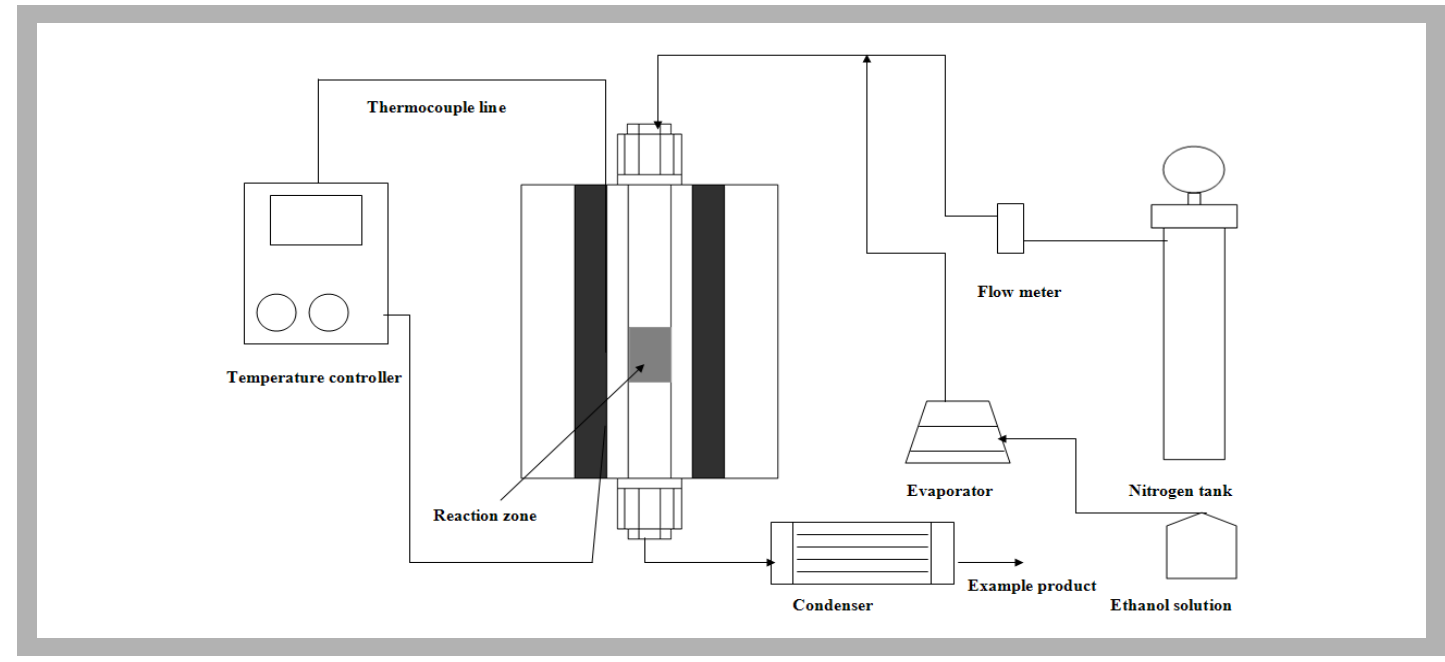

The adsorbent was packed in the fixed bed ( 0.4 inches ID (internal diameter); 15 inches depth). In a typical experiment, a $95 \%$ by weight ethanol solution was heated into vapor using an electric heating mantle and nitrogen was opened into the system for convection the ethanol vapor. Then, the adsorption system was controlled the temperature by furnace at 90 ${ }^{\circ} \mathrm{C}$. The exiting ethanol vapor was condensed using water as a cooling medium. The ethanol vapor condenses every three minutes; a volume of about $1 \mathrm{ml}$ was collected. Thus, the average flow of the condensate was about $1 \mathrm{ml} / \mathrm{min}$. The sample is kept after it analyszing the water content of the condensate by Karl Fischer titration. At the end of experiment, the percentage of ethanol between input and output is equal. Each sample is tested for three cycles. For the next cycle of adsorption, the furnace temperature is increased to $250 \mathrm{C}$ and fed nitrogen into the system for about $2 \mathrm{hr}$ to remove water from the bed. The system is operated for three cycles after finishing each sample. 


\section{Results and Discussions}

\subsection{Type of zeolite}

The type of zeolite was identified using the XRD pattern. For this work, the XRD of the zeolite products at various fusion temperatures are presented in Fig. 3, Fig. 4, and Fig. 5. According to these XRD patterns, the main phase of zeolite in the present work has only sodium aluminum silicate hydrate $\left(1.08 \mathrm{Na}_{2} \mathrm{O} \cdot \mathrm{Al}_{2} \mathrm{O}_{3} \cdot 1.68 \mathrm{SiO}_{2} \cdot 1.8 \mathrm{H}_{2} \mathrm{O}\right)$.

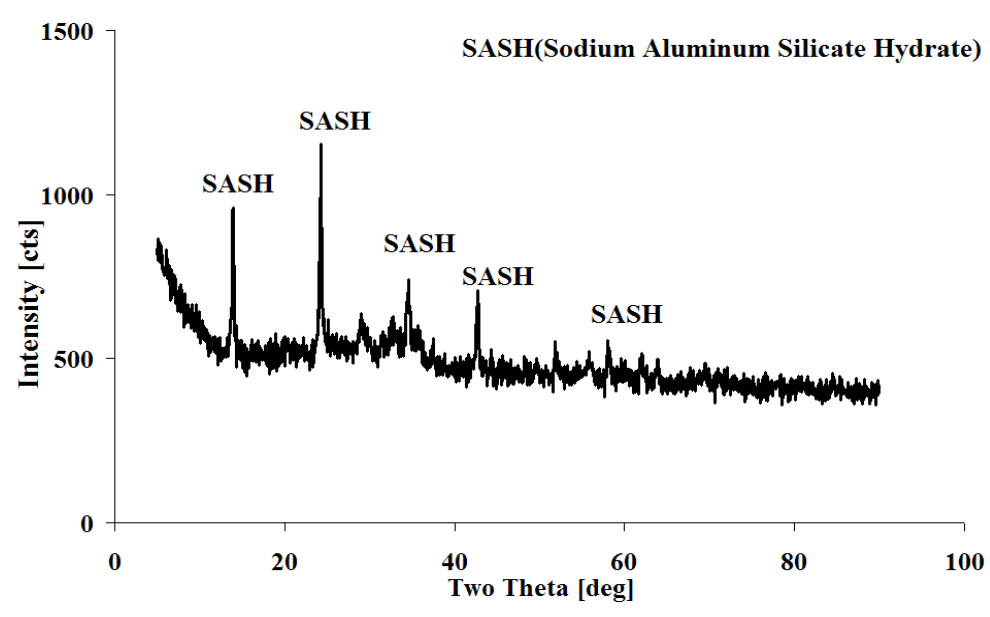

Figure 3

Scheme of XRD of zeolite infusion temperature at $450^{\circ} \mathrm{C}$

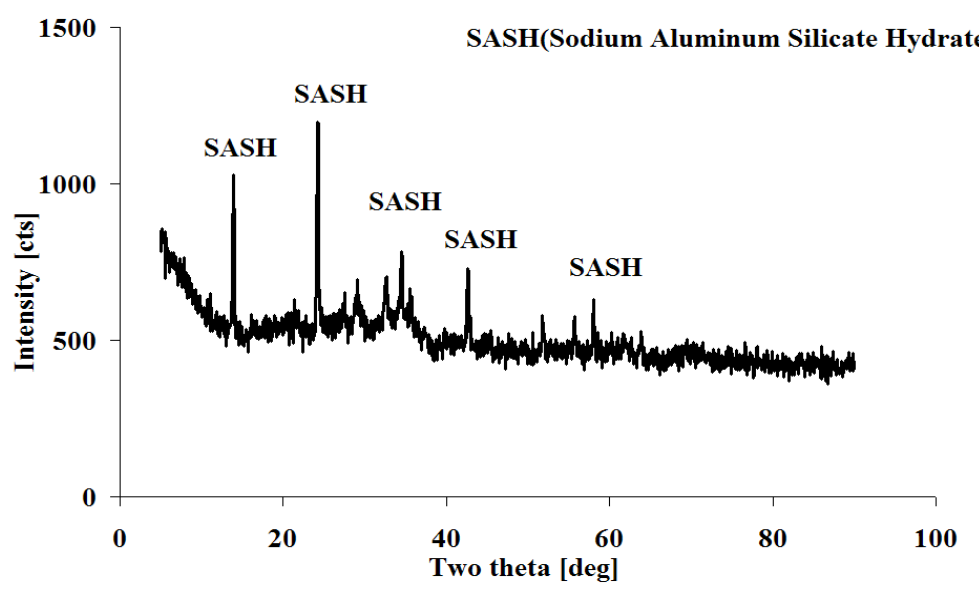

Figure 4

Scheme of XRD of zeolite infusion temperature at $550^{\circ} \mathrm{C}$

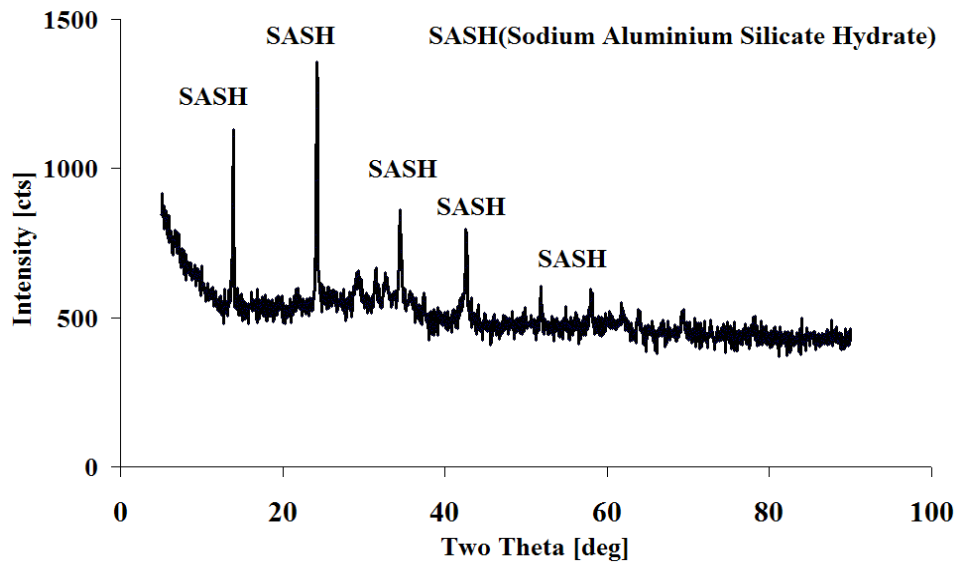

Figure 5

Scheme of XRD of zeolite infusion temperature at $650^{\circ} \mathrm{C}$ 


\subsection{Effects of adsorption time and adsorption}

Firstly, the synthesized materials were tested for water adsorption by packing $1 \mathrm{~g}$ of these materials (after being dried overnight in the oven) in the fixed-bed reactor at 90 ${ }^{\circ} \mathrm{C}$ and $1 \mathrm{~atm}$. The starting solution contained $95 \%$ ethanol in vapor phase and the test was carried out for $17 \mathrm{~min}$ and three cycles. Figs. 6-8 present the ability of water removing in term of ethanol purity at the outlet of the reactor with time (and adsorption cycles). The adsorption performance decreases with time until $17 \mathrm{~min}$, from which the outlet ethanol concentration is closed to the starting concentration (95\%). After the first cycle, the sample was regenerated by purging nitrogen at $250^{\circ} \mathrm{C}$ to remove water from the pores of the sorbent. Then, it was re-tested for water adsorption as the second and third cycles. From the second and third cycles, it was found that the adsorption capacities are in the same range as that of the first cycle. Furthermore, in some case, the adsorption capacities are relatively higher than the first cycle; this could be due to use of high temperature $\left(250^{\circ} \mathrm{C}\right)$ under inert gas (nitrogen flow) for regeneration. At high temperature, all water in the pores of the material can be efficiently removed compared to the drying overnight for the first cycle, in which some water molecule might be remain in the pore of the sample. In addition, according to the adsorption process, it is not only related to the pore of material for retaining substance molecule but also examining the interaction between molecule of substance and the location for attaching of molecule. Therefore; the higher adsorption capacities for the second and third cycles could be due to the temperature for evaporating water from samples is high enough to destroy the interaction of molecule. Furthermore, the purging of nitrogen through the system can help eliminate air molecules in the pores of the samples as well as remove the moisture from tube reactor.

\subsection{Adsorption capacity of synthesized zeolites}

A series of experiments was undertaken to determine the effect of fusion temperature on zeolite formation under conditions described for each method. The ability of removing water from ethanol solution at various adsorption times (from 3-17 $\mathrm{min}$ ) is presented in Fig. 6 (fusion temperature $450^{\circ} \mathrm{C}$ ), Fig. 7 (fusion temperature $550^{\circ} \mathrm{C}$ ) and Fig. 8 (fusion temperature $650^{\circ} \mathrm{C}$ ). Clearly, the highest percentage of ethanol solution was sample 1 (fusion at $450^{\circ} \mathrm{C}$ ), from which above $99 \%$ ethanol concentration can be achieved. It can also be seen from these figures that the adsorption capacity decreased with increasing adsorption time due to the saturate of samples. The reusability of all samples was also performed. After removing adsorbed water by increasing temperature under air flow, the tests were carried out for second and third time. It is clear that all samples presented well-reusability.

Figure 6

Graph of water removal capability in sample 1 (fusion temperature at $\left.450^{\circ} \mathrm{C}\right)$

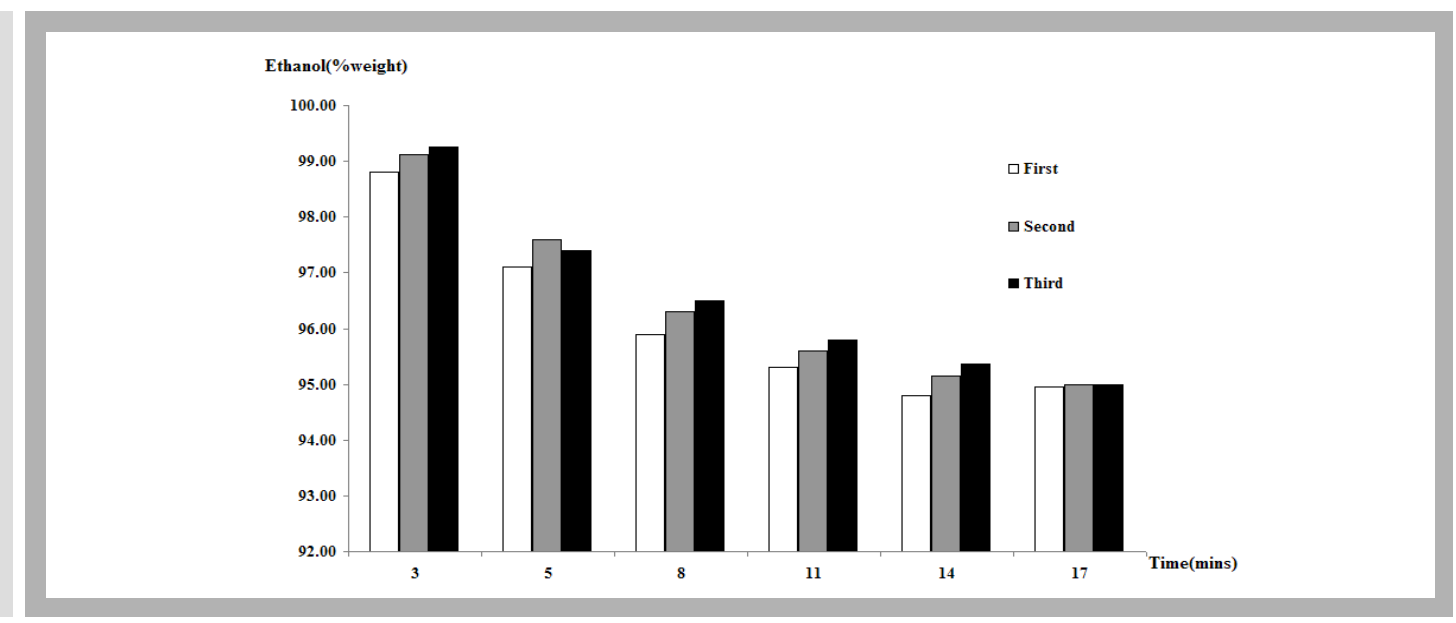




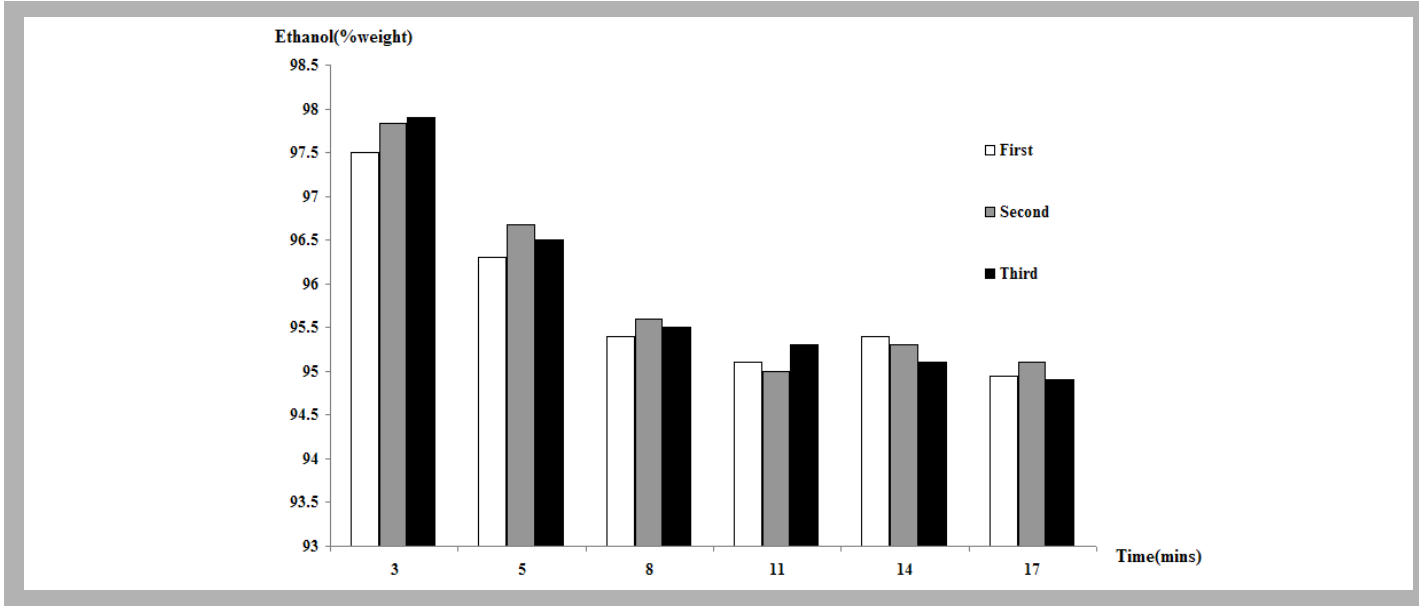

Figure 7

Graph of water removal capability in sample 2 (fusion temperature at $\left.550^{\circ} \mathrm{C}\right)$

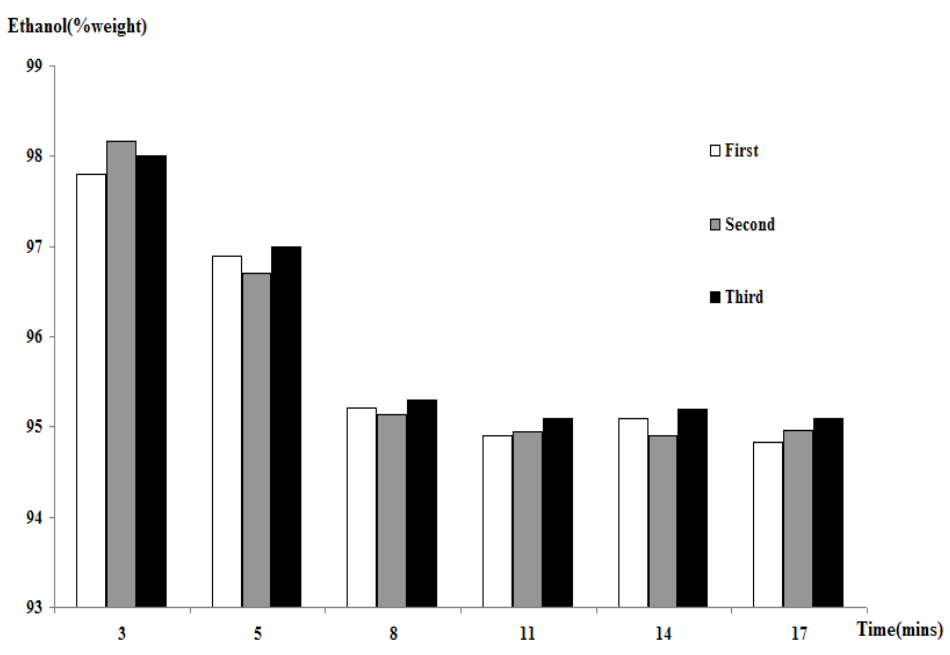

Figure 8

Graph of water removal capability in sample 3 (fusion temperature at $\left.650^{\circ} \mathrm{C}\right)$

For comparison, the adsorption perofrmance of a commercial-grade molecular sieve was also tested and compared to all three synthesized samples. As shown in Fig. 9, it can be seen that the adsorption performance of sample 1 was closed to that of commercial-grade molecular sieve.

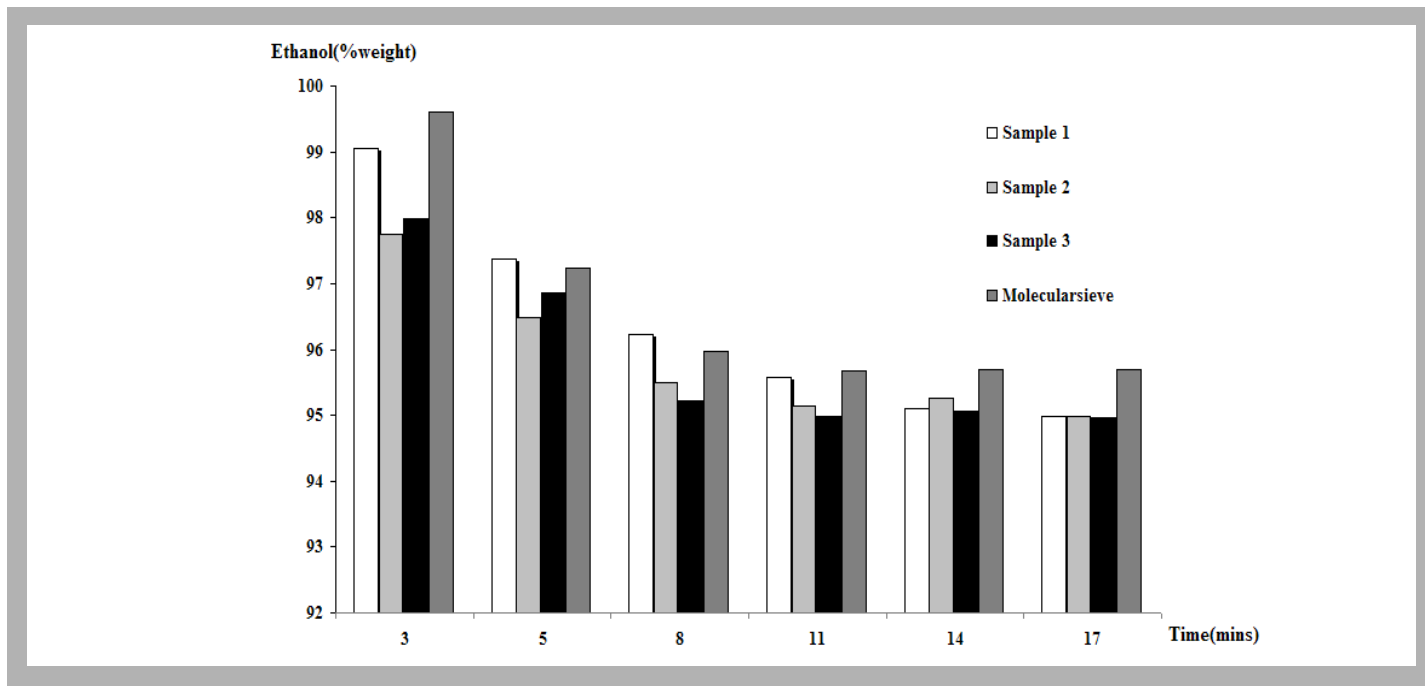

Figure 9

Scheme of ability for water removal

in samples compare to the molecular sieve

To understand the performance achievement, the XRF and BET experiments perfomed as presented in Table 1. This result indicated that the fusion treatment significantly increases the specific surface area of CFA; in addition, $\mathrm{Na}_{2} \mathrm{O}$ was also found after the treatment, which helped to form zeolite crystallization. Although BET measurement indicated that sample 3 has highest surface area (about $69.136 \mathrm{~m}^{2} / \mathrm{g}$ ), the adsorption performance was less than 
sample 1 since sample 1 shows greater composition of $\mathrm{Na}_{2} \mathrm{O}$ (about $18.05 \%$ ) with relatively comparable specific surface area (about $58.312 \mathrm{~m}^{2} / \mathrm{g}$ ).

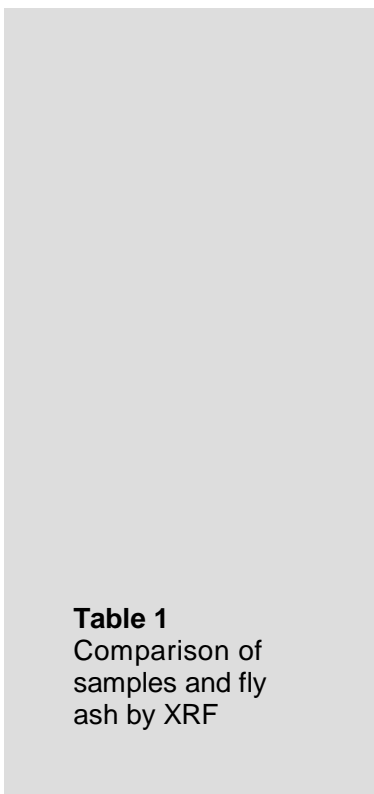

\begin{tabular}{c|c|c|c|c}
\hline \multicolumn{6}{l}{ Composition(\%concentration) } & Fly ash & Sample 1 & Sample 2 & Sample 3 \\
\hline $\mathrm{Na}$ & & & & \\
$\mathrm{MgO}$ & - & 18.05 & 15.98 & 14.88 \\
$\mathrm{Al}_{2} \mathrm{O}_{3}$ & 1.51 & 1.03 & trace & 1.24 \\
$\mathrm{SiO}_{2}$ & 14.77 & 14.84 & 13.26 & 14.46 \\
$\mathrm{SO}_{3}$ & 26.8 & 25.59 & 25.36 & 26.02 \\
$\mathrm{~K}_{2}$ & 7.3 & 3.18 & 3.04 & 2.91 \\
$\mathrm{CaO}$ & 3.16 & 0.45 & 0.25 & 0.00 \\
$\mathrm{TiO}_{2}$ & 18.12 & 13.42 & 14.31 & 14.09 \\
$\mathrm{Fe}_{2} \mathrm{O}_{3}$ & 2.22 & 1.59 & 1.77 & 1.68 \\
$\mathrm{NiO}$ & 25.12 & 21.34 & 25.45 & 23.92 \\
$\mathrm{SrO}_{\mathrm{ZrO}}$ & 0.25 & 0.29 & 0.35 & 0.35 \\
$\mathrm{BaO}_{\mathrm{Rb}}$ & 0.18 & 0.12 & 0.15 & 0.14 \\
$\mathrm{Y}_{2} \mathrm{O}_{3}$ & 0.33 & 0.09 & 0.09 & 0.10 \\
& trace & trace & trace & trace \\
Surface area $\left(\mathrm{m}^{2} / \mathrm{g}\right)$ & 0.05 & - & - & - \\
& 0.21 & - & - & - \\
\hline
\end{tabular}

\section{Conclusions}

Zeolite was successfully synthesized from Coal Fly Ash (CFA) by fusion method at $450^{\circ} \mathrm{C}$. The specific surface area of $58.312 \mathrm{~m}^{2} / \mathrm{g}$ with the main phase of Sodium Aluminum Silicate Hydrate $\left(1.08 \mathrm{Na}_{2} \mathrm{O} \cdot \mathrm{Al}_{2} \mathrm{O}_{3} \cdot 1.68 \mathrm{SiO}_{2} \cdot 1.8 \mathrm{H}_{2} \mathrm{O}\right)$ can be achieved. According to the adsorption testing, this synthesized material can efficiently adsorb water from ethanol solution with the highest percentage more than $99 \%$ ethanol (from the starting of $95 \%$ ethanol); this performance is comparable to the commercial-grade molecular sieve.

\section{ACKNOWLEDGEMENT}

This work was financially supported by The Joint Graduate School of Energy and Environment. 


\section{REFERENCES}

[1] S. Chirarattananon and S. Nirukkanaporn, "Deregulation of ESI and privatization of state electric utilities in Thailand," Energy Policy, vol. 34, no. 16, pp. 2521-2531, 2006.

[2] S. S. Rayalu, J. S. Udhoji, K. N. Munshi, and M. Z. Hasan, "Highly crystalline zeolite-a from fly ash of bituminous and lignite coal combustion," Journal of Hazardous Materials, vol. 88, no. 1, pp. 107-121, 2001.

[3] X. Querol, et al., "Synthesis of zeolite from coal fly ash: an overview," International Journal of Coal Geology, vol. 50, no. 1-4, pp. 412-423, 2002.

[4] V. K. Jha, M. Nagae, M. Matsuda, and M. Miyake, "Zeolite formation from coal fly ash and heavy metal ion removal characteristics of thus-obtained Zeolite X in multi-metal systems," Journal of Environmental Management, vol. 90, no. 8, pp. 2507-2514, 2009.

[5] D. Ruen-ngam, D. Rungsuk, R. Apiratikul, and P. Pavasant, "Zeolite formation from coal fly ash and its adsorption potential," Journal of the Air \& Waste Management Association, vol. 59, no. 10, pp. 1140-1147, 2009.

[6] N. Shigemoto and H. Hayashi, "Selective formation of Na-X zeolite from coal fly ash by fusion with sodium hydroxide prior to hydrothermal reaction," Journal of Materials Science, vol. 28, no. 17, pp. 4781-4786, 1993.

[7] A. Molina and C. Poole, "A comparative study using two methods to produce zeolites from fly ash," Minerals Engineering, vol. 17, no. 2, pp. 167-173, 2004. 